\title{
Empirical Study of Parents' Perceptions of Preschool Teaching Competencies in China
}

\author{
Zhuo Cui, Martin Valcke, Ruben Vanderlinde \\ Department Educational Studies, Ghent University, Gent, Belgium \\ Email: zhuo.cui@Ugent.be
}

Received 14 October 2015; accepted 16 February 2016; published 23 February 2016

\begin{abstract}
Parents play an important role in children's education. Parents' expectations and evaluation of kindergarten teachers could foster the collaboration between kindergarten teachers and parents. However, parents' voice has largely been ignored in empirical research. The purpose of the present study is to reveal 3 - 6 years old children's parents' perceptions about 1) the importance of new kindergarten teacher standards and 2) their perceptions about kindergarten teachers' mastery of these standards. In this study, considering China's new Kindergarten Teacher Professional Standards (2012) has been defined and implemented recently. China is used as a case based on a survey of 423 parents. The results show that "respect" and "love" to children are the most important competencies. Parents speak highly of teachers' mastery levels. Both parental expectations to their children and family involvements are significant impact factors to parents' cognition and assessment of kindergarten teachers' competencies.
\end{abstract}

\section{Keywords}

Kindergarten Teacher, Parents, Preschool Education, Standards

\section{Introduction}

During the last decade consensus has shown that preschool education is not only the first but also a very critical stage in view of the development and lifelong learning of children [1]. Since promising positive benefits are directly related to the quality of Early Childhood Education and Care (ECEC), an increase has been observed in viewing ECEC as a policy priority and teaching program in many countries [2]. However, the majority of teacher preparation programs are less successful in providing adequate training to aspiring teachers, leaving them unable to accommodate the increasingly rigorous instructional goals of public schools or meeting the increasing complexity of the educational reality [3].

Facing the increasing challenges in educational landscape, teaching professionals start reform movements in many parts of the world. A growing number of policy-makers and educators have such established Teacher Professional Standards to improve the quality of preschool teacher education [4]. Especially during recent years, innovative sets of national/state standards have been developed and put forward in many countries (e.g., United Kingdom, United States, Canada, Australia and China). In 2012, the Chinese Ministry of Education put forward new professional standards for-among others-kindergarten teachers. The "Professional Standards for Kin- 
dergarten Teachers (2012)" is expected to contribute to initial teacher education and teachers' professional development. The standards provide a framework that incorporates ethics, knowledge, practical skills and other required professional capacities to be adopted during kindergarten teachers' careers.

Centrally developed standards cannot ignore parental influences on children achievement and development. A study, for example, the origin of the American Kindergarten standards, shows the weak involvement of the target group in their conception [5]. Previous studies [6] [7] present empirical evidence for the beneficial impact of parental involvement in kindergarten contexts. The position of parents as key stakeholders is also critical when acknowledging that children's academic achievement is affected by family's Socio-Economic Status (SES), parental expectations and the quality of the home environment [8] [9]. This brings researchers to the conclusion that without a close participation of a child's family, school educational programs are threatened to be less effective [10]. This explains why numerous researches focus on parent involvement in early childhood education, for example, to the need for sharing responsibilities between teachers and parents on 0-6 year-old children's education [11]. However, the relationships between teachers and their young students' parents are often characterized as tense, full of misunderstanding, and struggle [12] [13].

In order to understand preschool parents' perceptions and assess kindergarten teachers' competencies, this research centers on an empirical study of how parents perceive kindergarten teachers given their different involvement in school and educational aspirations.

The first research focuses on what parents expect from kindergarten teachers. In the present study, we analyze what parents expect from kindergarten teachers by asking them how important they judge the individual standards from the view of their child. There is little research that involves parents in such an exercise. A rare example is a Jordanian study, which asks parents to discuss the requirements of high quality kindergarten programs [14]. Secondly, we invite parents - on the base of the new standards list - to rate the mastery level of their children's kindergarten teachers. Again, few literature is available that focuses on parents' perception of teachers' quality indicator. Most available research builds on kindergarten teachers' reflections [15], care takers' perceptions of personal professionalism [16] or policy analysis frameworks and professional development [17].

Parents can express very different opinions as to what they consider to be important and how they rate the mastery of kindergarten teachers. As stated earlier, this can be linked to contextual factors, such as SES. As an indicator of social economic status, in the present study, parents are divided in different groups according to the rural or urban setting of the family and the General Domestic Product (GDP) of the regions where families live.

Next, parents differ in their opinions considering their level of involvement and their expectations about preschool-based education. Earlier research revealed how stronger school-family connections result in a higher impact of kindergarten education [18] [19]. Closely related to the latter, research also has shown how parent expectations play a critical role in the impact of kindergarten education [20]. Therefore, the family involvement and parental expectations on their children are two of impact factors which contribute to the importance parents attach to the different standards and the perceived mastery of these competences by their kindergarten teachers.

\section{Research Design}

\subsection{Research Instruments}

To study parent's perceptions a new scale was developed: the Parents' Perception \& Assessment Questionnaire (PPAQ). This scale is based on the Teacher Professional Standards (2012). Parents are invited to rate on a Likert-scale to understand to what extent 1) they consider this standard to be important in view of the education of their child at school and 2) they judge kindergarten teacher's mastery of this standard. Cronbach's $\alpha$ is 0.96 for the "importance" part of the scale and 0.88 for the mastery part of the scale. In impact factors section, two scales were utilized to measure the difference between rural and urban areas: Scale of Educational Aspirations and Expectations (SEAE) (Jacob, 2010); Family Involvement Questionnaire (FIQ) (Fantuzzo, Tighe, Childs, 2000). Focusing on preschool education period, SEAE $(\alpha=0.83)$ was consisted of 8 questions in 3 different subsequent sections: expectations and valuing of education; stability of expectations and aspirations; congruency for higher educational attachment. In FIQ, three-factor solution revealed through exploratory factor analysis is defined by the following constructs: school-based involvement; home-based involvement; home-school conferencing.

\subsection{Research Sample}

To cater for the large differences in the China context, and capture the differences in SES, three regions in China 
were selected. The three regions reflect three different GDP levels: Beijing (High), Sichuan (Medium), Heilongjiang (Low). In the three geographical areas, parents from both urban and rural areas were studied. In the urban areas study, 3 big cities were selected in view of data collection: Beijing (the capital of China), Harbin (the capital city in Heilongjiang Province), Chengdu (the capital city in Sichuan Province). In the rural areas study, 9 villages were selected for data collection (Junzhuang, Miaofengshan, Tanzhesi, Xinli, Sheli, Liaodian, Xilai, Shou'an, Fuxing). Ten kindergarten schools (5 urban and 5 rural) were purpose-fully selected to represent different socioeconomic variations within each region (total 30 schools). The majority (85\%) of them are public schools. From each school, parents were randomly selected for the study. This resulted in 600 parents of 3 6-year old children were invited to participate in the study (200 participants in each region). A total of 423 (Beijing: 172, Heilongjiang: 144, Sichuan: 104, Missing: 3) completed questionnaires were returned. Participants' age ranged from 23 to 65 years $(M=31.7, S D=9.6)$. Approximately $60 \%$ of the parents lived in urban areas and $40 \%$ in rural areas.

Besides, interviews also have been conducted: 60 parents from Beijing, Heilongjiang and Sichuan were investigated in this research. Half of them came from county side; others are from big cities. Considering SES factors, parents from different classes were selected in this project. Additionally, the interviewed parents are from different types of kindergartens in order to provide multiple and diversified data sources.

PPAQ consists of 5 sections: background information, the importance of Kindergarten Teacher Professional Standards, the evaluation of attaining Kindergarten Teacher Professional Standards, impact factors and open questions. In addition, a 12-questions interview was carried out on a one-to-one basis, which varied from 25 to 60 minutes. 6 questions were asked, which are related to parents' perceptions and expectations of kindergarten teachers and preschool education; 3 questions were related to parental assessment and satisfaction on their children's kindergarten teachers' competencies; 2 questions were related to parents' involvement and relationships with kindergartens; 1 question was related to Kindergarten Teacher Preschool Standards (2012). Digital recordings were used to all participants in their convenient places (mainly in their homes or classrooms). All interviews were subsequently transcribed in order to avoid mistakes and the misunderstandings from notes or impressions. Meanwhile, in-depth interviews were expected help to understand if kindergarten teachers have mastered the new standards and the parents' expectations on good kindergarten teachers.

The SPSS statistical software Program (version 20.0) was used to compile statistics and analyze the collected data. The ANOVA test was used to determine the extent to which the independent variables (urban/rural, sociodemographic characteristics and parents' SES) influenced parents' assessments and perceptions on teachers.

\section{Research Results}

\subsection{Descriptive Results}

A questionnaire was designed to investigate the parental perceptions and their assessment to kindergartens teachers in China. A number of 600 parents of 3 - 6-year old children were participated in this study (200 participations in each region). A PPAQ was designed and sent to the selected sample, together with a cover letter with the consent for participation in research. A total of 423 (Beijing: 172, Heilongjiang: 144, Sichuan: 104, Missing: 3) questionnaires were returned. Survey participants ( $N=408$, missing: 15) ranged in the age from 23 to 65 years $(M=31.7, S D=9.6)$. Approximately $60 \%$ of the parents are in urban areas, and $40 \%$ are from rural areas. 10 kindergartens (5 urban and 5 rural) are purpose-fully selected to represent different socioeconomic variations within each regions (total 30 kindergartens). The majority of investigated kindergartens (85\%) are public schools.

\subsection{Importance}

From the analysis, it shows both urban and rural parents have similar judgments to the importance of 14 competencies that kindergarten teachers are supposed to have based on "Kindergarten Teacher Professional Standards (2012)". In interviews, parents tend to take "Love" "Patient" "Patient" and "Knowledgeable" as four key words in the conversation. More than $80 \%$ parents expect that kindergarten teachers could be like mothers to their children in schools. This result is consistent with the interview result in this study.

There is no significant difference between three selected regions in terms of "Importance" evaluation. Furthermore, the difference between rural and urban areas has been indicated. Among the 14 evaluation questions, 
only one has obvious high scored difference $(\mathrm{P}=0.017)$ between urban parents and rural parents: "Being respecting to children and paying attention to the physical and mental health of children.” Parents from urban ranked this competency the first place (Score: 9.92) among 14 competencies; However, parents from rural areas ranked this competency the third place (Score: 9.74). This indicated that urban parents tend to pay more attention to the physical and mental health of children, therefore, they have stricter requirement to teacher's professional competency on this area. Parents from rural areas hold the opinion that the most important competency of kindergarten teachers is "Being with love, responsibility, patience, optimistic, enthusiastic, affinity and careful.”(Score: 9.76). However, parents from urban areas placed this competency at the third important place (Score: 9.84) among the 14 competencies. The highest score (9.76) given by parents who come from rural areas is similar with the average score (9.75) given by parents from urban. There are 7 kindergarten teacher competency scores from urban parents are higher than the highest score (9.76) from rural parents. The highest scores from urban and rural families are very close to each other. However the scores of the first seven questions from urban families are higher than those from rural families.

\subsection{Mastery}

Based on the investigation, no significant difference in "Mastery" analysis existed between Beijing, Heilongjiang and Sichuan. Among the 14 items, "Improving communication with colleagues and sharing experiences and knowledge for collaborated development; to be effective in communication and cooperation with parents” was recorded at first place by parents. It implied parents agree that most of their children’s kindergarten teachers master this competency in the Kindergarten Teacher Professional Standards. "Having relevant natural science and social science knowledge as well as corresponding artistic appreciation and knowledge on modern information technology” was marked the lowest records among 14 competencies. In parents' opinion, kindergarten teachers are not well knowledgeable. In the interviews, parents have similar feedbacks about this. When comparing the geographical difference of urban and rural parents, not much difference was found in these 14 kindergarten teachers' competencies in the "Standard”.

\subsection{Parental Educational Aspirations and Expectations (SEAS)}

Urban parents have higher expectations to their children's study. However, the children of rural parents understand their parents' expectations more clearly. When parents were asked "My hopes and dreams to my child’s education have changed with their growth", it indicated urban parents tend to have relative stable expectations on their children's education. Besides, the expectations to their children from rural parents tend to be adjusted accordingly with the growing of their children.

In interviews, parents from urban areas pay more attention to the knowledge scope learned in kindergartens. In urban areas, most of parents are worried about their children's school readiness. They want their children can learn some knowledge what should be learned in elementary schools during kindergarten period, in order to solve school readiness problems. However, in rural areas, most of parents choose to give more time for children to play instead of learning knowledge. Although China government has issued policies to prohibit teaching preliminary school's courses in preschool, many parents expressed that they will teach their children reading. Many rural kindergartens, particularly private kindergartens, tend to teach preliminary school courses in advance and incorporate the management scheme of preliminary school.

\subsection{Parent Involvement in Children's Education}

School based involvement was investigated in the research. Rural parents have more active presences in the activities (e.g., volunteering) organized by kindergartens and they are willing to join plans and class trips with their children. However, the parents from urban are more supportive to each other. In interviews, all of parents have strong motivation to participate children's school activities. The activity which needs parents corporate with children to participate is most welcomed by parents. Home based involvement was revealed as well in the research. Urban parents provide more studying materials such as DVDs, setting up reading area in home and they tend to take their children to zoos and museums for more additional studying opportunities of special knowledge. In the interview, some parents hold the point that family education is an important part in preschool education. These parents buy many educational materials for their children to practice what children have 
learned from kindergarten teachers. For example, one parent said her daughter was not very good at singing or dancing, so she downloaded the same songs which her daughter learned in kindergarten, and helped her daughter to practice them at home.

Home and school based involvement was tested in the research. Rural parents are more willing to discuss the problems of their children in the kindergarten with teachers and try to figure out the solutions. Besides, they are more willing to communicate with kindergarten teachers and also present the problems of their children in home to teachers. In the interview, when parents were asked about how to communicate with children's teachers, most of parents agree that pick-up time is the best time to get the connection with teachers. Making phone calls and sending SMS are important approaches to keep in touch with teachers. Additionally, some parents say that blogs, forums and other mobile apps bring more useful paths for parents to communicate with teachers and other parents. However, in rural areas, many families are living very far away from kindergartens and children take school buses to go to kindergartens. Therefore, making phone calls is the most regular way for them to know children's behavior in class from kindergarten teachers.

\subsection{Linear Regression Analysis}

A linear regression analysis was taken to reveal how FIQ and SEAS predict the importance of the standards. The influence of FIQ and SEAS to parents' cognition of teachers' competencies was estimated via the equation: Yi= $103.865+\mathrm{X} 1 * 0.397+\mathrm{X} 2 * 0.019$. $\mathrm{X} 1$ is overall score of SEAE and $\mathrm{X} 2$ is overall score of FIQ. Yi is the overall score of importance cognition by parents (total 14 items).

FIQ and SEAS predict the perceived teachers' mastery of the standards. The influence of FIQ and SEAS to parents' assessment of teachers' competencies was estimated via the equation: $\mathrm{Ym}=86.194+\mathrm{X} 1 * 0.486+\mathrm{X} 2$ * 0.048. X1 is overall score of SEAE and X2 is overall score of FIQ. Ym indicates the overall score of kindergarten teachers' mastery level evaluated by parents (total 14 items).

\section{Conclusions \& Discussion}

Based on "Kindergarten Teacher Professional Standards (2012)", this research has demonstrated the importance and mastery of kindergarten teachers' competencies on a number of parental replication through both qualitative and quantitative data analyses. This paper analyzed the parents' evaluation to kindergarten teachers' professional development in 14 items and found that parents from both urban and rural have slightly difference in terms of the performance of kindergarten teachers.

Nowadays, an increasing number of Chinese people from rural areas move to big cities to earn more money. Additionally, with the development of mass media, the differences between rural and urban or different regions are increasingly less. From parents' opinion, "respect" and "love" to children are the most important competencies of kindergarten teachers. With the increasing of parents' education level, as well as the development of preschool education, more and more parents notice that professional education concept is more important than professional knowledge and skills. Parents from both urban and rural areas give high scores to kindergarten teachers' mastery levels. In this study, although Chinese parents are satisfied with their children's teachers, they pointed out that kindergarten teachers should be better educated and be more knowledgeable in the future. Urban parents have better expectations on their children's achievement. They tend to provide more wide range studying materials and opportunities to promote children's full development. However, both parental expectations to their children and parents' involvement are two key impact factors to parents' cognition and assessment on teachers' competencies. Parents, who have higher expectations to their children or who spend more time in participating children's education, tend to think kindergarten teachers' competencies are more important to their children. Besides, these parents give higher scores on their children's teachers. In China, urban parents tend to have a single child comparing with rural parents. Most of families are structured by 6 adults and 1 child, so the security problem of their children is taken as super important to families. As a result, they tend to have more strict requirements to teachers.

According to this study, the parents who were interviewed are satisfied with teacher's work and understand that kindergarten teacher is a relative hard job. Most of the parents think "love" to children from kindergarten teachers is key important. In terms of teachers' professional knowledge and expertise, it is difficult for parents to evaluate. Instead of fully understanding the current professional development status of teachers, the evaluations are more likely conducted superficially, for example, through the feedbacks from children, the observation in 
opening day, and the interactions when they take children home from kindergarten. Besides, many parents have limited capabilities to evaluate the professional development status of teachers.

Although numerous methods were utilized to make the survey accessible to as many parents as possible, there were parents who didn't have opportunities to take part in. Worrying to their children, parents who were asked to evaluate kindergarten teachers' mastery levels may don't answer questions truthfully. In the future, it will be possible to estimate more kinds of parents from different regions. In following studies, self-evaluation of professional mastery levels by kindergarten teachers will be taken. Principles and educators' assessment from kindergarten teachers will be considered as well in next step research.

\section{References}

[1] Ugaste, A., Tuul, M., Niglas, K. and Neudorf, E. (2013) Estonian Preschool Teachers’ Views on Learning in Preschool. Early Child Development and Care, 184, 370-385. http://dx.doi.org/10.1080/03004430.2013.788502

[2] OECD (2012) Starting Strong III. A Quality Toolbox for Early Childhood Education and Care. OECD, Paris.

[3] National Council on Teacher Quality (2013) State Teacher Policy Yearbook. Washington DC.

[4] Day, C., Elliot, B. and Kington, A. (2005) Reform, Standards and Teacher Identity: Challenges of Sustaining Commitment. Teaching and Teacher Education, 21, 563-577. http://dx.doi.org/10.1016/j.tate.2005.03.001

[5] Camp, D.G. (2007) Where Do Standards Come from? A Phenomenological Study of the Development of National Board Early Childhood/Generalist Standards. Journal of Research in Childhood Education, 21, 420-437. http://dx.doi.org/10.1080/02568540709594605

[6] Kohen, D. and Guèvremont, A. (2014) Income Disparities in Preschool Outcomes and the Role of Family, Child, and Parenting Factors. Early Child Development and Care, 184, 266-292. http://dx.doi.org/10.1080/03004430.2013.785539

[7] Colley, B.M. (2014) Voices from the Gambia: Parents’ Perspectives on Their Involvement in Their Children's Education. Childhood Education, 90, 212-218. http://dx.doi.org/10.1080/00094056.2014.910977

[8] Davis-Kean, P.E. (2005) The Influence of Parent Education and Family Income on Child Achievement: The Indirect Role of Parental Expectations and the Home Environment. Journal of the Division of Family Psychology of the American Psychological Association, 19, 294-304. http://dx.doi.org/10.1037/0893-3200.19.2.294

[9] Iruka, I.U., Dotterer, A.M. and Pungello, E.P. (2014) Ethnic Variations of Pathways Linking Socioeconomic Status, Parenting, and Preacademic Skills in a Nationally Representative Sample. Early Education and Development, 25, 973994. http://dx.doi.org/10.1080/10409289.2014.892806

[10] Gökalp, M., Barut, Y. and Mentese, S. (2010) Pre-School Education and the Effects of the Relations between Parents and Teachers on Pre-School Age Children (Ordu Centrum). Procedia-Social and Behavioral Sciences, 9, 203-212. http://dx.doi.org/10.1016/j.sbspro.2010.12.137

[11] Guerra, M. and Luciano, E. (2010) Sharing the Responsibility of Education: The Relationship between Teachers and Parents in 0-6 Year-Old Children Services and Schools. Procedia-Social and Behavioral Sciences, 2, 3308-3313. http://dx.doi.org/10.1016/j.sbspro.2010.03.506

[12] De Steno, H. (2000) Parent Involvement in the Classroom: The Fine Line. Young Children, 55, 13-17.

[13] File, N. (2001) Family-Professional Partnerships: Practice That Matches Philosophy. Young Children, 56, 70-74.

[14] Abu Taleb, T.F. (2013) Requirements of High-Quality Kindergarten Programs According to Jordanian Parents: An Exploratory Study. Journal of Research in Childhood Education, 27, 472-484. http://dx.doi.org/10.1080/02568543.2013.822953

[15] Goldstein, L.S. (2007) Beyond the DAP versus Standards Dilemma: Examining the Unforgiving Complexity of Kindergarten Teaching in the United States. Early Childhood Research Quarterly, 22, 39-54. http://dx.doi.org/10.1016/j.ecresq.2006.08.001

[16] Martin, S., Meyer, J., Jones, R., Laverne, N. and Ling, T. (2010) Perceptions of Professionalism among Individuals in the Child Care Field. Child \& Youth Care Forum, 39, 341-349. http://dx.doi.org/10.1007/s10566-010-9107-5

[17] Eun Kyeong, C. and Couse, L. (2008) Early Childhood Teacher Policy in the United States: Continuing Issues, Overcoming Barriers, and Envisioning the Future. International Journal of Child Care and Education Policy, 2, 15-30. http://dx.doi.org/10.1007/2288-6729-2-2-15

[18] Galindo, C. and Sheldon, S.B. (2012) School and Home Connections and Children’s Kindergarten Achievement Gains: The Mediating Role of Family Involvement. Early Childhood Research Quarterly, 27, 90-103. http://dx.doi.org/10.1016/j.ecresq.2011.05.004

[19] Kim, E.M., Coutts, M.J., Holmes, S.R., Sheridan, S.M., Ransom, K.A., Sjuts, T.M. and Rispoli, K.M. (2012) Parent 
Involvement and Family-School Partnerships: Examining the Content, Processes, and Outcomes of Structural versus Relationship-Based Approaches. CYFS Working Paper No. 2012-6, Nebraska Center for Research on Children, Youth, Families and Schools.

[20] Froiland, J.M., Peterson, A. and Davison, M.L. (2012) The Long-Term Effects of Early Parent Involvement and Parent Expectation in the USA. School Psychology International, 0143034312454361. 